\title{
Comparative Study of Magnetic Properties and Microstructure for As-cast and Square-wave Pulse Current Joule Annealed Wires
}

\author{
Jingshun Liu ${ }^{a}$, Hongxian Shen ${ }^{b}$ Yandong Jia ${ }^{b}$, Dongming Chen ${ }^{b}$, Zhaoxin Du ${ }^{a}$, \\ Yongquan Han ${ }^{a}$, Wen Ma ${ }^{a}$,Jianfei Sun ${ }^{b}$ \\ a School of Materials Science and Engineering, Inner Mongolia University of Technology, \\ Hohhot 010051, China \\ ${ }^{b}$ School of Materials Science and Engineering, Harbin Institute of Technology, Harbin 150001, China
}

Received: September 7, 2014; Revised: August 31, 2015

\begin{abstract}
We here report on a comparative study of the microstructure and magnetic properties of as-cast and SPCJA-ed Co-based wires for potential sensor applications. Experimental results indicate that both as-cast and SPCJA-ed wires exhibit typical amorphous feature. There also exists the enhanced local ordering degree of atomic arrangement and obvious transformation (maximum magnetic permeability and minimum saturation magnetization) of magnetic properties after SPCJA treatment, resulting from variation of magnetic moment exchange coupling and magnetic anisotropy by coactions of high-density pulsed magnetic field energy and thermal activation energy. Moreover, SPCJA treatment can drastically improve the GMI property of melt-extracted wires. GMI ratio $\left[\Delta Z / Z_{0}\right]_{\max }$ of $166.07 \%$ and field response sensitivity $\xi_{\max }$ of $413.76 \%$ /Oe by more than 2.25 times and 1.73 times of as-cast wire at $5 \mathrm{MHz}$. Therefore, the SPCJA-ed wire exhibits the improved GMI and magnetic properties at $5 \mathrm{MHz} \sim 10 \mathrm{MHz}$ in contrast to AC annealed wire, which is more suitable for GMI sensor applications working at low-applied-frequency and relatively low-working-magnetic field.
\end{abstract}

Keywords: amorphous microwires, Square-wave Pulse Current Joule Annealing (SPCJA), GMI property, microstructure, sensor applications

\section{Introduction}

Recent investigations attracted much interest and indicated the novel giant magnetoimpedance (GMI) Co-based amorphous microwires are the excellent candidate materials for the weakly magnetic field detection of potential GMI sensor applications ${ }^{1,2}$. Compared with rotating water-spinning and glass-covered melt-spinning techniques, melt-extracted microwire exhibits higher solidification rate and unique super-soft magnetic properties ${ }^{3-5}$. Most of all, there exists an important trend for choosing more sensitive GMI materials: exploring novel magnetic microwires with enhanced GMI and magnetic properties. However, this final purpose of melt-extracted Co-based amorphous microwires can be realized by using some efficient Joule annealing techniques, especially alternating current according to the special geometric shape ${ }^{6,7}$.

As previously reported, Zhou et al. ${ }^{8}$ investigated that the effect of AC Joule-heating annealing for melt-spun CoFeSiB amorphous ribbon on GMI property, influencing the easy direction magnetization, magnetic anisotropy and domain structure, and their $\left[\Delta Z / Z_{0}\right]_{\max }$ increased to about $180 \%$ at $900 \mathrm{kHz}$ for special annealing conditions of $30 \mathrm{~min}$ and an AC current density of $2.8 \times 10^{7} \mathrm{~A} / \mathrm{m}^{2}$. Sinha et al. ${ }^{9}$ observed $[\Delta Z / Z]_{\max }$ of CoMnSiB glass-coated microwire increased from $66 \%$ of as-cast to $129 \%$ after short-duration PC annealing with amplitude of $100 \mathrm{~mA}$, due to the increase of outer shell

*e-mail: jingshun_liu@163.com domain volume. Atalay et al. ${ }^{10}$ investigated that the variation relationship between magnetization and Young's modulus of PC-treated $\mathrm{Fe}_{77.5} \mathrm{Si}_{7.5} \mathrm{~B}_{15}$ amorphous wires, and measured the coercivity and anisotropic energy density with the variation of current intensity and tensile stress, further revealed the proper PC annealing compared with other traditional annealing can effectively release inner residual stress and improve the soft magnetic property. Generally, the magnetic properties are closely related to microstructures yielded by Joule annealing from structure-property perspective ${ }^{11}$. Generally, square-wave pulse current Joule annealing (SPCJA) as a distinctive Joule-heating modulation technique for obtaining application-oriented magnetically sensitive materials, in comparison with the other convention current annealing, it also can effectively avoid the induced crystallization phenomenon by relatively large current density, including improving magnetic anisotropy and microstructural relaxation with an excellent GMI effect under high-density pulse or alternating circumferential magnetic field ${ }^{12}$. However, there also lacks the comparative study on magnetic properties and microstructure of as-cast and SPCJA-ed microwires, so it is worthwhile to explore the related investigation on the relation of GMI properties and microstructure of as-cast and SPCA-ed wire.

In this paper, we aim to comparatively present the magnetic properties and microstructure of as-cast and SPCJA-ed microwires by using X-ray diffraction (XRD), 
high-resolution transmission electron microscopy (HRTEM) and magnetic property measurement including precision impedance analyzer, and identify the current annealed wires with superior GMI properties for potential sensor applications.

\section{Experimental Details}

In this experiment, mother alloy ingot with the nominal composition of $\mathrm{Co}_{68.2} \mathrm{Fe}_{4.3} \mathrm{~B}_{15} \mathrm{Si}_{12.5}$ (in at. \%) was prepared by arc-melting in purified argon atmosphere and copper mould casting methods, then setting the top-end of club-shaped alloy into BN crucible with a diameter of $8 \mathrm{~mm}$, and it was re-melted by induction coil in precision melt-extraction facility, so the microwires with a diameter of $30 \mu \mathrm{m}$ were extracted by the edge of a high-speed rotating copper wheel also in purified argon. Square-wave pulse current Joule annealed (SPCJA) was conducted by passing through amorphous wire a square-wave alternating current (with a frequency of $50 \mathrm{~Hz}$, the average current intensity $I_{\mathrm{m}}$ of $75 \mathrm{~mA}$ and duration time of 480s, air cooling, A.C.) supplied by a mini-type self-designed PC annealing device ${ }^{12,13}$, and the main technique parameters including $50 \mathrm{~Hz}, 75 \mathrm{~mA}$ and $480 \mathrm{~s}$ were explored as the optimized indexes by a large number experiments of numerical simulation for the transient temperature rise during SPCJA process, as described in Liu et al. ${ }^{11}$, while it is important to assure the wire still to be amorphous state after this treatment. On the other hand, once the frequency decreases below $50 \mathrm{~Hz}$, the improvement of practical action will deteriorate approaching to the effect of DC annealing. Even the time extends for a longer time, it seem to no obvious effect on GMI property as the time is up to the critical times (i.e. 480 s or 600 s) based on a great deal of previous experiments ${ }^{11-14}$.

As-prepared and SPCJA-ed microwires were examined by $\mathrm{X}$-ray diffraction with $\mathrm{CuK}$ radiation (XRD, Rigaku D/max- $\gamma \mathrm{B}$ ), high-resolution transmission electron microscopy (HRTEM, JEM 2010F). The magnetic properties were performed by vibrating sample magnetometer (VSM, LakeShore 7407)

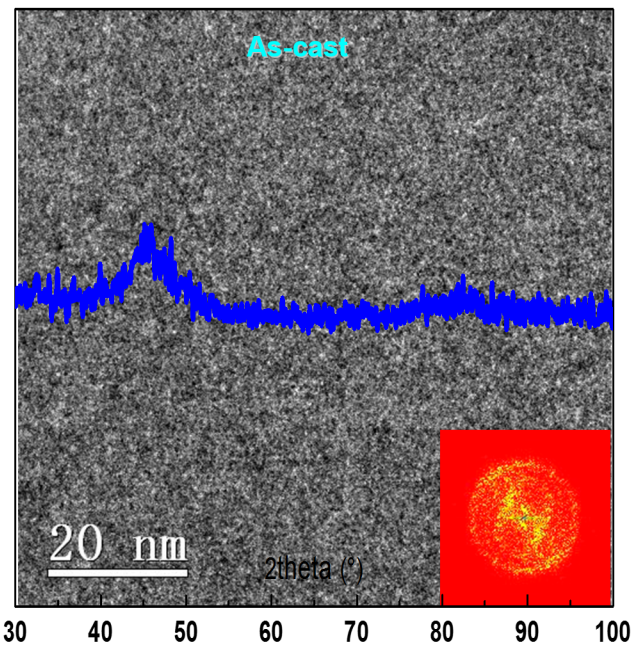

(a) with a maximum applied field of $0.2 \mathrm{~T}$. The impedance measurements were performed using Aligent 4294A precision impedance analyzer at frequencies $40 \mathrm{~Hz} \sim 110 \mathrm{MHz}$. And the effective sample length for impedance measurement is about $22 \mathrm{~mm}$. GMI ratio, $\Delta Z / Z_{0}$, is defined as $^{13}$ :

$$
\frac{\Delta Z}{Z_{0}}(\%)=\left[\frac{Z\left(H_{e x}\right)-Z\left(H_{0}\right)}{Z\left(H_{0}\right)}\right] \times 100 \%
$$

and magnetic field response sensitivity, $\xi$, is expressed as ${ }^{14}$ :

$$
\xi=\frac{d\left[\frac{\Delta Z}{Z_{0}}(\%)\right]}{d H_{e x}}
$$

where $Z\left(H_{\mathrm{ex}}\right)$ is the impedance under different external field, $H_{\text {ex }}$ is below 4.50e supplied by a pair Helmholtz coils paralleling to the wire-axis to avoid the disturbance of geomagnetic field. $Z\left(H_{0}\right)$ is the initial impedance at $0 \mathrm{Oe}$. All measurements were conducted at room temperature.

\section{Results and Discussion}

Figure 1 displays X-ray diffraction patterns and HRTEM images of as-cast and SPCJA-ed wires. Both XRD patterns consist of one broad diffused diffraction maximum, and these indicate that the microstructure of wires entirely consists of amorphous structure before and after SPCJA. While their surface morphology and is extreme smooth, uniform and almost with no obvious formation of nanocrystalline, which is consistent with the above obtained XRD results, and their corresponding fast Fourier transformation (FFT) images just consist of halo rings, which also exhibits the mainly amorphous feature. Moreover, there is an enhanced degree of local ordering (i.e. atomic arrangement) for SPCJA-ed microwires versus as-cast state statistically calculated by auto-correlation function (ACF) technique of Digital Micrograph software (not shown here). Namely, SPCJA

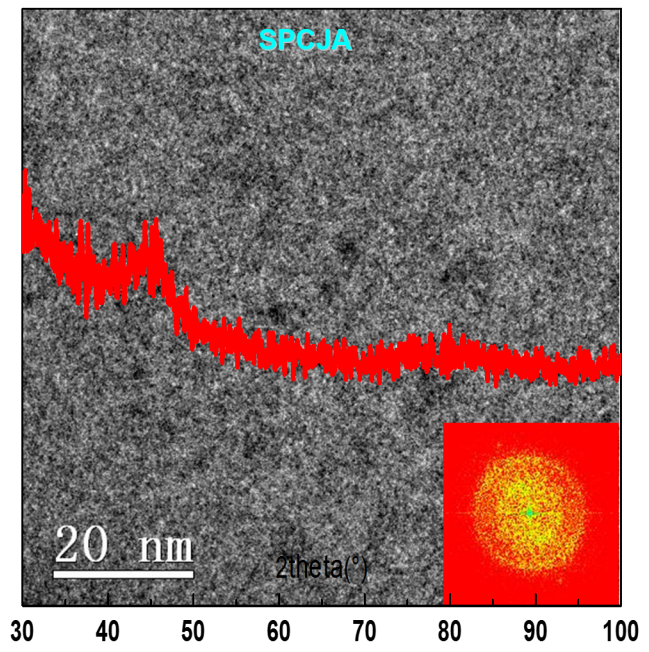

(b)

Figure 1. XRD patterns and corresponding HRTEM images including the insets of selected area electronic diffraction (SAED) patterns of as-cast microwire (a) and SPCJA-ed microwire (b). 
treatment can improve atomic diffusion by releasing internal stress and finally forming the regularly arranged atomic micro-regions under the action of thermal activation and high-density alternating current magnetic field energy during SPCJA. Herein, the SPCJA-ed wire is tending to possessing so excellent magnetic properties.

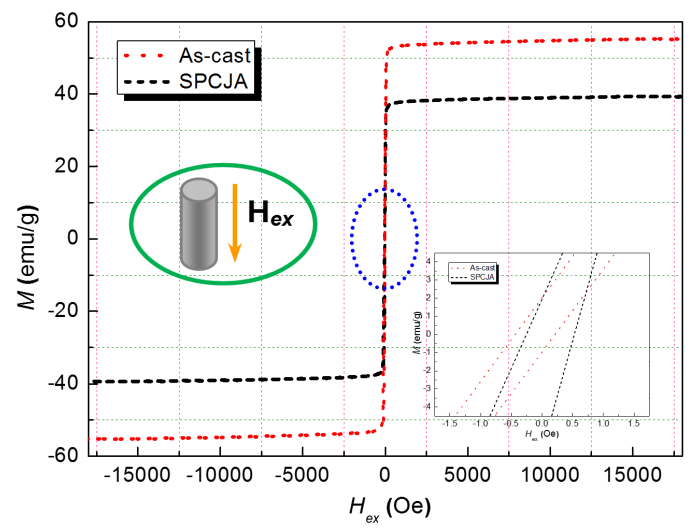

Figure 2. Longitudinal $M-H$ hysteresis loops including a magnified central area of as-cast and SPCJA-ed microwires. The uni-directional arrow indicates the direction of external magnetic field $H_{\mathrm{ex}}$.
Figure 2 reveals the longitudinal $M-H$ magnetic hysteresis loops of as-prepared and SPCJA-ed microwires. Their shapes of hysteresis loops are almost rectangles, which exhibit an excellent soft magnetic feature, so their magnetization can easily reach the saturation state at low magnetic field ${ }^{15}$. According to the magnified central area of loops, the coercivity $H_{\mathrm{c}}$ slightly increases from $0.28 \mathrm{Oe}$ of as-cast wire to $0.55 \mathrm{Oe}$ of SPCJA-ed wire, and the saturation magnetization $M_{\mathrm{s}}$ decreases from $51.66 \mathrm{emu} / \mathrm{g}$ of as-cast to $39.41 \mathrm{emu} / \mathrm{g}$ of SPCJA-ed wire, and the maximum magnetic permeability $\mu_{\mathrm{m}}$ from 0.71 of as-cast wire to 0.93 of SPCJA-ed wire. While the electrical resistivity $\rho_{\mathrm{m}}$ increases from $122.71 \mu \Omega \cdot \mathrm{cm}$ of as-cast wire to $149.58 \mu \Omega \cdot \mathrm{cm}$ of SPCJA-ed wire. Accordingly, the enhanced magnetic properties of SPCJA-ed wire could be attributed to the change of local ordering degree of atomic arrangement and the formation of stably circular magnetic domains, resulting in a notable increase of magnetic moment exchange coupling drived by external magnetic field ${ }^{16}$.

Figure 3 shows the $3 \mathrm{D}$ variation images of impedance and their corresponding GMI ratio $\Delta Z / Z_{0}$ dependence of external magnetic field $H_{\text {ex }}(0 \sim 5.0 \mathrm{Oe})$ in range of frequency $(100 \mathrm{kHz} \sim 15 \mathrm{MHz}$ ) for as-cast and SPCJA-ed (annealing at $75 \mathrm{~mA}$ for $480 \mathrm{~s}$ at $50 \mathrm{~Hz}$ ) microwires. Compared to these GMI profiles (including impedance and GMI ratio variations), all of them take on smooth variation and almost have no obviously
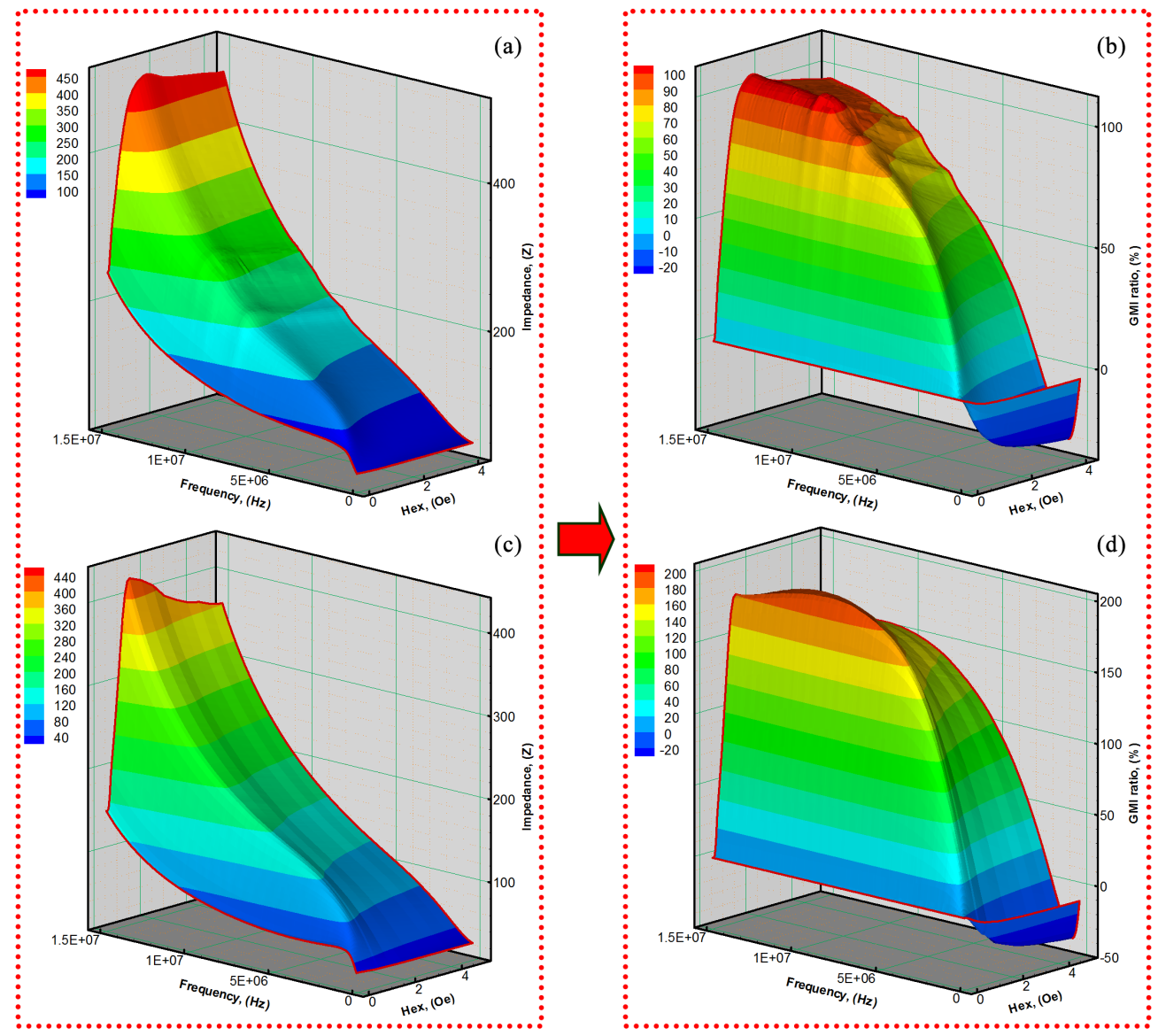

Figure 3. 3D images of impedance (a) and (c) and their corresponding GMI ratio $\Delta Z / Z_{0}$ (b) and (d) dependence of external magnetic field $H_{\mathrm{ex}}(0 \sim 5.0 \mathrm{Oe})$ in range of frequency $(100 \mathrm{kHz} \sim 15 \mathrm{MHz})$ for as-cast and SPCJA-ed $(50 \mathrm{~Hz}, 75 \mathrm{~mA}, 480 \mathrm{~s})$ microwires, respectively. 
macroscopic fluctuant variation with increasing magnetic field at different frequency. Meanwhile, the SPCJA-ed microwire has relatively lower values of initial impedance and maximum impedance, namely excellent GMI property (this mainly indicates the larger GMI ratio $\left[\Delta \mathrm{Z} / \mathrm{Z}_{0}\right]$ ).

Further to explore the specific comparison of GMI property, we conduct the corresponding statistic in following discussion part by using 3D variation images. Herein, Figure 4 shows that the dependence of GMI ratio $\Delta Z / Z_{0}$ on external magnetic field $H_{\mathrm{ex}}(0 \sim 4.5 \mathrm{Oe})$ of as-cast and SPCJA-ed microwires and frequency dependence of magnetic field response sensitivity $\xi_{\max }(\% / \mathrm{Oe})$ and its corresponding GMI peak position $H_{\mathrm{p}}$ at selected frequencies of SPCJA-ed microwire. It is nearly consistent with above mentioned GMI profiles, all curves of both wires increase rapidly at first (nearly at $0 \sim 1.0 \mathrm{Oe}$ ) then decreases monotonically or keeps small variation with an increase of external magnetic field at the selected frequencies. In details, $\left[\Delta \mathrm{Z} / \mathrm{Z}_{0}\right]_{\max }$ values of as-cast wire are $-28.96 \%, 52.73 \%, 73.73 \%, 85.61 \%$, $105.38 \%, 104.69 \%$ and $104.80 \%$ at $1 \mathrm{MHz}, 3 \mathrm{MHz}, 5 \mathrm{MHz}$, $7 \mathrm{MHz}, 10 \mathrm{MHz}, 12 \mathrm{MHz}, 15 \mathrm{MHz}$, respectively, as shown in Figure $4 \mathrm{a}$. Notably, the $\Delta \mathrm{Z} / \mathrm{Z}_{0}$ curve at $1 \mathrm{MHz}$ of as-cast wire exhibits the negative GMI effect with increasing field as a result of inhomogeneous distribution of the locally critical field of magnetization rotation. $\left[\Delta \mathrm{Z} / \mathrm{Z}_{0}\right]_{\max }$ values of
SPCJA-ed wire are $28.76 \%, 118.81 \%, 166.07 \%, 185.96 \%$, $193.50 \%, 190.32 \%$ and $180.40 \%$ at $1 \mathrm{MHz}, 3 \mathrm{MHz}, 5 \mathrm{MHz}$, $7 \mathrm{MHz}, 10 \mathrm{MHz}, 12 \mathrm{MHz}, 15 \mathrm{MHz}$, respectively, as seen in Figure 4b. Especially, at 5MHz, SPCJA-ed wire has larger $\left[\Delta Z / Z_{0}\right]_{\max }$ of $166.07 \%$, maximum field sensitivity $\xi_{\max }$ of $413.76 \% / \mathrm{Oe}$ and relatively larger $H_{\mathrm{p}}=0.9 \mathrm{Oe}$ in comparing with as-cast of GMI effect ( $H_{\mathrm{p}}$ corresponds to the working magnetic field range of sensor ${ }^{17}$, as shown in Figure 4), which are nearly 2.25 times of $73.69 \%$ and 1.73 times of $239.5 \% / \mathrm{Oe}$ and $H_{\mathrm{p}}=0.8 \mathrm{Oe}$ for as-cast wire respectively. At $10 \mathrm{MHz}$, SPCJA-ed wire also has relatively higher $\left[\Delta Z / Z_{0}\right]_{\max }$ of $193.50 \%, \xi_{\max }$ of $380.81 \% / \mathrm{Oe}$ and $H_{\mathrm{p}}=1.0 \mathrm{Oe}$ comparing with as-cast of GMI effect, which are nearly 1.84 times of $105.38 \%$, nearly 1.37 times of $278.56 \% / \mathrm{Oe}$ and $H_{\mathrm{p}}=1.3 \mathrm{Oe}$ for as-cast wire respectively. Importantly, the larger $\left[\Delta Z / Z_{0}\right]_{\max }, \xi_{\max }$ and $H_{\mathrm{p}}$ at relatively low frequency is tend to enhance the resolution and accuracy of GMI sensor from sensor application perspective, so the better working frequency is chosen as $5 \mathrm{MHz}$ according to the sensor applied frequency ranges $(5 \mathrm{MHz} 10 \mathrm{MHz})$ as shown in Figure $4 \mathrm{c}$. Furthermore, SPCJA (annealing at $75 \mathrm{~mA}$ for $480 \mathrm{~s}$ at $50 \mathrm{~Hz}$ ) annealed wire possesses an enhanced GMI property at $5 \mathrm{MHz}$ in comparison with the corresponding results reported by previously reference ${ }^{14}$, such as the values of $\left[\Delta Z / Z_{0}\right]_{\max }$, $\xi_{\max }$ and $H_{\mathrm{p}}$ of ACJA-treated (at $75 \mathrm{~mA}$ for $480 \mathrm{~s}, 50 \mathrm{~Hz}$ )

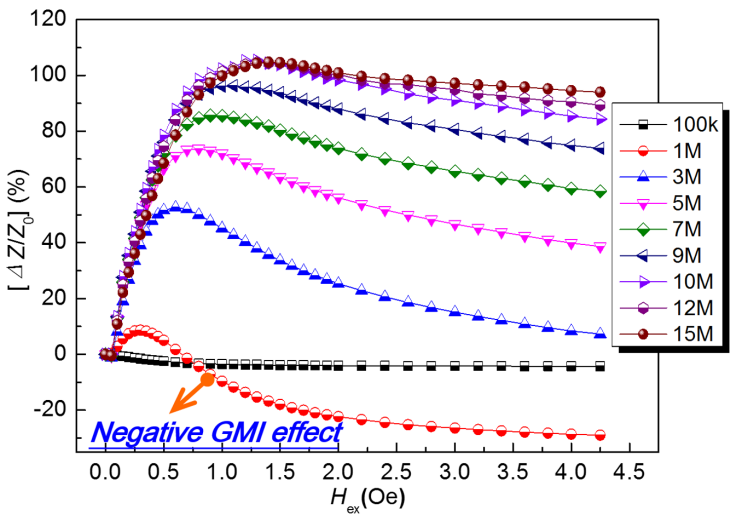

(a)

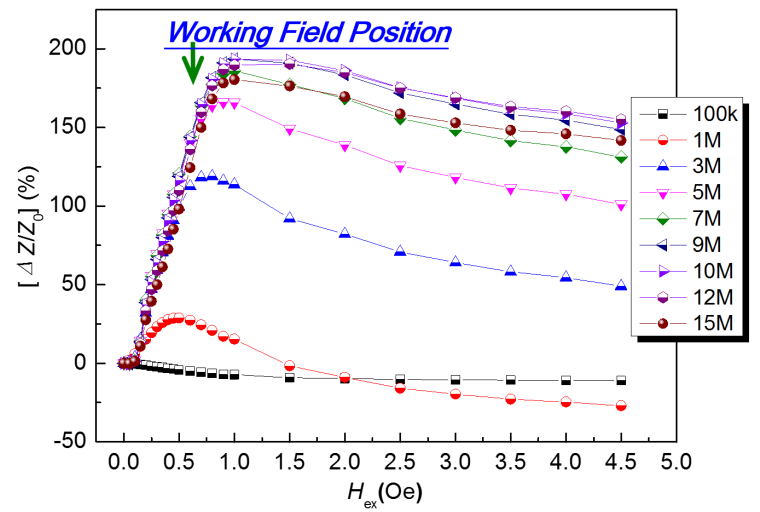

(b)

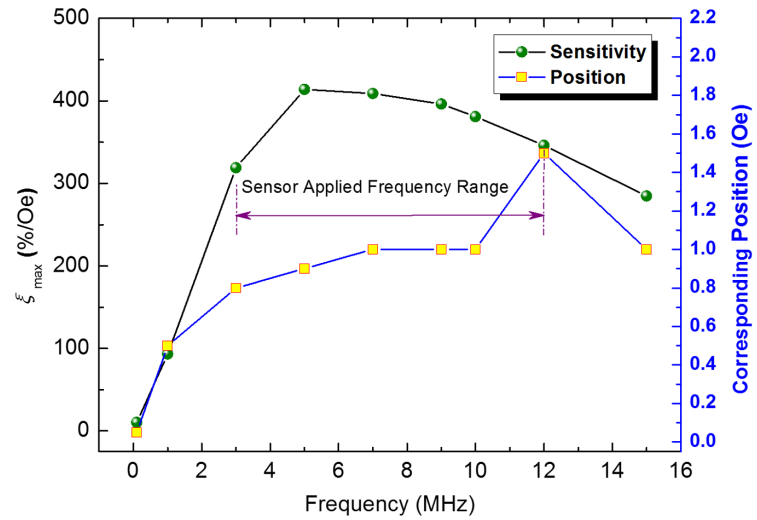

(c)

Figure 4. Variation curves of GMI ratio $\Delta Z / Z_{0}$ dependence of external magnetic field $H_{\text {ex }}$ at selected frequencies of as-cast (a) and SPCJA-ed (b) microwires. Frequency dependence of magnetic field response sensitivity $\xi_{\max }(\% / \mathrm{Oe})$ and its corresponding GMI peak position $H_{\mathrm{p}}$ at selected frequencies of SPCJA-ed microwire. The bidirectional arrow in (c) indicates the sensor applied frequency range of $5 \mathrm{MHz} 10 \mathrm{MHz}$. 
achieve to $142.33 \%, 181.21 \% / \mathrm{Oe}$ and $0.8 \mathrm{Oe}$ at $5 \mathrm{MHz}$, respectively. Significantly, the square pulse is more effective than "sin" wave annealing owing to both the high-density pulsed circumferential magnetic field and thermal activation energy in relatively long active time for increasing magnetic anisotropy and improving microstructural relaxation. In a word, SPCJA technique is more suitable for applying as the magnetic sensitive materials working at low-frequency and relatively high-magnetic field of GMI sensor.

\section{Conclusions}

As a novel class of GMI sensor that contains high-performance sensitive materials, SPCJA-ed microwires exhibit an excellent and attractive engineering magnetic property. In summary, SPCJA treatment has remarkable effect on GMI properties, and the SPCJA (at $75 \mathrm{~mA}$ for $480 \mathrm{~s}$ at $50 \mathrm{~Hz}$, A.C.) annealed wire possesses the excellent magnetic properties including slightly larger coercivity and smaller saturation magnetization, higher magnetic permeability. At $5 \mathrm{MHz},\left[\Delta Z / Z_{0}\right]_{\max }$ value of SPCJA-ed wire increases to $166.07 \%$, which is nearly

\section{References}

1. Phan MH and Peng HX. Giant magnetoimpedance materials: fundamentals and applications. Progress in Materials Science. 2008; 53(2):323-420. http://dx.doi.org/10.1016/j.pmatsci.2007.05.003.

2. Vázquez M and Hernando A. A soft magnetic wire for sensor applications. Journal of Physics D: Applied Physics. 1996; 29(4):939-949. http://dx.doi.org/10.1088/0022-3727/29/4/001.

3. Chiriac H and Óvári TA. Amorphous glass-covered magnetic wires: preparation, properties, applications. Progress in Materials Science. 1996; 40(5):333-407. http://dx.doi.org/10.1016/S00796425(97)00001-7.

4. Vázquez M. Soft magnetic wires. Physica B, Condensed Matter. 2001; 299(3-4):302-313. http://dx.doi.org/10.1016/ S0921-4526(01)00482-3.

5. Zhukova V, Zhukov A, García K, Kraposhin V, Prokoshin A, Gonzalez J, et al. Magnetic properties and GMI of soft meltextracted magnetic amorphous fibers. Sensors and Actuators. A, Physical. 2003; 106(1-3):225-229. http://dx.doi.org/10.1016/ S0924-4247(03)00172-9.

6. Zhukov A. Design of the magnetic properties of fe-rich, glass-coatedmicrowires for technical applications. Advanced Functional Materials. 2006; 16(5):675-680. http://dx.doi. org/10.1002/adfm.200500248.

7. Qin FX and Peng HX. Ferromagnetic microwires enabled multifunctional composite materials. Progress in Materials Science. 2013; 58(2):183-259. http://dx.doi.org/10.1016/j. pmatsci.2012.06.001.

8. Zhou XZ, Tu GH, Kunkel H and Williams G. Effect of Jouleheating annealing conditions on giant magnetoimpedance of co-rich amorphous ribbons. Sensors and Actuators. A, Physical. 2006; 125(2):387-392. http://dx.doi.org/10.1016/j. sna.2005.07.017.

9. Sinha S, Das B and Mandal K. Magnetoimpedance of a glasscoated amorphous microwire. Journal of Applied Physics. 2009; 105(7):07A311. http://dx.doi.org/10.1063/1.3068465.
2.25 times of $73.69 \%$ for as-cast wire, and the field response sensitivity $\xi_{\max }$ of SPCJA-ed wire increases to $413.76 \% / \mathrm{Oe}$ by more than 1.73 times of $239.5 \% / O$ for as-cast wire, even the GMI peak position of annealed wire tends to be $0.9 \mathrm{Oe}$ and $1.0 \mathrm{Oe}$ at $5 \mathrm{MHz}$ and $10 \mathrm{MHz}$ respectively. This type SPCJA-ed wires show an enhanced GMI property in contrast to AC-treated wire duo to the high-density pulse circumferential magnetic field. Therefore, it can be as a promising candidate sensitive material working at $5 \mathrm{MHz} 10 \mathrm{MHz}$ for potential high-performance GMI sensor applications.

\section{Acknowledgements}

This work was financially supported by National Natural Science Foundation of China (NSFC) under Grant nos. 51401111 and 51561026, Natural Science Foundation of Inner Mongolia Autonomous Region of China under Grant no. 2014BS0503, and Scientific Research Foundation of the Higher Education Institutions of Inner Mongolia Autonomous Region of China (SRFHEI) under Grant no. NJZY14062.

10. Atalay S, Squire P and Gibbs M. Pulse annealing of FeSiB amorphous wires. IEEE Transactions on Magnetics. 1993; 29(6):3472-3474. http://dx.doi.org/10.1109/20.281200.

11. Liu JS, Cao FY, Xing DW, Zhang LY, Qin FX, Peng HX, et al. Enhancing GMI properties of melt-extracted Co-based amorphous wires by Twin-zone joule annealing. Journal of Alloys and Compounds. 2012; 541:215-221. http://dx.doi.org/10.1016/j. jallcom.2012.05.126.

12. Liu JS, Du ZX, Jiang SD, Shen HX, Li Z, Xing DW, et al. Tailoring giant magnetoimpedance effect of Co-based microwires for optimum efficiency by self-designed square-wave pulse current annealing. Journal of Magnetism and Magnetic Materials. 2015; 385:145-150. http://dx.doi.org/10.1016/j.jmmm.2015.02.050.

13. Liu JS, Qin FX, Chen DM, Shen HX, Wang H, Xing DW, et al. Combined current-modulation annealing induced enhancement of giant magnetoimpedance effect of Co-rich amorphous microwires. Journal of Applied Physics. 2014; 115(17):17A326. http://dx.doi.org/10.1063/1.4865460.

14. Liu JS, Shen HX, Xing DW and Sun JF. Optimization of GMI properties by AC Joule annealing in melt-extracted Co-rich amorphous wires for sensor applications. Physica Status Solidi. A, Applications and Materials Science. 2014;211(7):1577-1582. http://dx.doi.org/10.1002/pssa.201431051.

15. Zhukov A, Ipatov M, Talaat A, Churyukanova M, Kaloshkin S and Zhukova V. Giant magnetoimpedance in thin amorphous and nanocrystalline microwires. Applied Physics. A, Materials Science \& Processing. 2014; 115(2):547-553. http://dx.doi. org/10.1007/s00339-013-8028-1.

16. Zhukov A, Talaat A, Ipatov M, Blanco JM, Gonzalez-Legarreta L, Hernando B, et al. Effect of nanocrystallization on magnetic properties and GMI effect of microwires. IEEE Transactions on Magnetics. 2014; 50:2501905. http://dx.doi.org/10.1109/ TMAG.2014.2303396.

17. Liu JS, Zhang DY, Cao FY, Xing DW, Chen DM, Xue X, et al. Multiangle combined magnetic-field annealing of Co-based amorphous microwires for sensor applications. Physica Status Solidi. A, Applications and Materials Science. 2012; 209(5):984989. http://dx.doi.org/10.1002/pssa.201127538. 